\title{
Small pore zeolite catalysts for furfural synthesis from xylose and switchgrass in a $\gamma$ - valerolactone/water solvent
}

Spencer M. Bruce, ${ }^{\mathrm{a}}$ Zhaowang Zong, ${ }^{\mathrm{b}}$ Anargyros Chatzidimitriou, ${ }^{\mathrm{c}}$ Leyla E. Avci, ${ }^{\mathrm{a}}$ Jesse Q. Bond, ${ }^{\mathrm{c}}$ Moises A. Carreon, ${ }^{\mathrm{b}}$ and Stephanie G. Wettstein ${ }^{\mathrm{a}^{*}}$

${ }^{a}$ Montana State University, Department of Chemical and Biological Engineering, 306 Cobleigh Hall, Bozeman, MT, USA. Fax: 01 406-994-3920; Tel: 01 406-994-5928; E-mail:

stephanie.wettstein@coe.montana.edu

${ }^{b}$ Colorado School of Mines, Chemical and Biological Engineering Department, 425 Alderson Hall, Golden, CO, USA. Fax: 01 303-273-3730; Tel: 01 303-273-3329

${ }^{c}$ Syracuse University, Department of Biomedical and Chemical Engineering, 121 Link Hall, Syracuse, NY, USA. Fax: 01 315-443-9175; Tel: 01 315-443-2550

*Corresponding author

\begin{abstract}
Small pore zeolites were evaluated as catalysts in the dehydration of xylose and biomass to furfural in a monophasic system of 90/10 $\gamma$-valerolactone (GVL)/water. Although the pore sizes were significantly smaller than the kinetic diameter of the sugars, furfural yields on the commercial SAPO-34 catalyst were $40 \%$ from xylose and $31 \%$ from switchgrass (considering total glucose and xylose moles). Furfural degradation with time was minimal. The SAPO-34 catalyst was recycled multiple times with only a 5\% drop in furfural yield and no significant leaching of acid sites occurred. To our knowledge, this is the first time that real biomass has been converted with moderate yields to furfural using small pore zeolites.
\end{abstract}

Keywords: Switchgrass, SAPO, small-pore zeolites, furfural, GVL

\section{Introduction}

With increased emphasis on reducing human dependence on traditional petroleum-derived fuels and chemicals, producing value-added chemicals from biomass has the potential to have a major global economic and environmental impact. The amount of plant biomass harvested annually worldwide is estimated to exceed 1.8 trillion tons, of which almost $95 \%$ is available as lignocellulosic biomass [1,2]. Lignocellulosic biomass is generally inedible for humans, making it an excellent candidate from which to derive important chemicals and fuels.

While lignocellulosic biomass is an attractive renewable material source, its implementation and use in chemical processes is complicated because of its complex and varying composition [3] that is primarily composed of cellulose (38-50\%), hemicellulose (23-32\%), and lignin (15$25 \%$ ) [4]. Among the chemicals that can be produced from lignocellulosic biomass, furfural, derived from the xylose predominant in the hemicellulose fraction, is of particular interest. Furfural has the potential to replace petroleum-based organics in the production of lubricants, adhesives, and plastics as well as act as a direct additive to fuel blends [5-7]. 
A significant body of research investigating the conversion of cellulose and hemicellulose into chemicals has focused primarily on either enzymatic [8-11] or mineral acid catalysis [12, 13]. While both of these methods are able to achieve some level of success, they also present a major issue for scale-up and commercialization: namely, separation of the catalyst from the reaction mixture due to solids formation (e.g., humins) and its subsequent reuse or recycling. In order to improve the catalyst separation, a solution of $\gamma$-valerolactone (GVL) and water can be used as a solvent. This solvent has been shown to solubilize corn stover [7, 14] and corn cobs [15], and therefore allows for a simple filtration step to separate heterogeneous catalysts from the solution $[1,7,16-18]$. Using heterogeneous catalysts eliminates the need for neutralization of mineral acids before disposing of them as waste or prior to further upgrading. Researchers have demonstrated that porous acid catalysts have the potential to fill an interesting niche in sugar dehydration chemistry if their catalytically active sites can be stabilized. Possible heterogeneous catalysts for the conversion of sugars to platform chemicals include micro- and mesoporous solid acid materials such as mesoporous silicas, ion-exchange resins, and zeolites.

Mesoporous silicas have shown 40-70\% furfural yield from xylose [7, 19], minimum diffusion limitations, and the potential to tune acid sites (surface functionalization); however, these phases are typically hydrothermally unstable, and therefore, are difficult to regenerate [20]. Ion-exchange resins have shown the highest yields to date along with minimum diffusion limitations, but their hydrothermal stability is limited, and leaching of acid sites into the solution can occur $[21,22]$. Medium pore size zeolites with pore apertures in the 5-5.5 $\AA$ range are appealing candidates as they demonstrate a molecular sieving effect since the kinetic diameter of major sugars derived from biomass are $6.8 \AA[23,24]$ (xylose) and $8.6 \AA$ [25] (glucose). Medium pore zeolites have shown high hydrothermal stability, are easy to regenerate, and can contain a high amount of Brønsted acid sites, which promote the conversion of xylose into furfural [26, 27]; however, studies have shown that some medium pore zeolites are less hydrothermally stable than small pore zeolites [28, 29].

A variety of zeolites have been studied as catalysts for the conversion of xylose to furfural. The highest reported yields were obtained using the medium pore zeolite mordenite, which resulted in a furfural yield of nearly $80 \%$ at $448 \mathrm{~K}$ in a $90 / 10 \mathrm{wt} \% \mathrm{GVL} /$ water solvent [7]. In 1:3 volume ratio of water and toluene at $443 \mathrm{~K}$, mordenite and faujasite both resulted in furfural yields of approximately $25 \%$ at xylose conversions of $30 \%$, which slightly increased to $42 \%$ and $34 \%$ yield at a conversions of $41 \%$ and $66 \%$, respectively [30]. Other zeolites, including H-beta $[7,31]$ and ZSM-5 [7, 32, 33] have been used for xylose dehydration with varying yields (40$70 \%$ ) of furfural, and large pore silicoaluminophosphates (SAPO-11, SAPO-40, and SAPO-5) in water/toluene solvent and $443 \mathrm{~K}$ resulted in furfural yields of 20-40\% [34]. No studies were found that reported conversion of biomass using zeolites as catalysts.

Small pore zeolites may offer higher hydrothermal stability [28, 29] and higher selectivity due to their pore size allowing less side reactions [35]. Herein, the potential for the catalytic conversion of xylose and switchgrass to furfural is studied over three small pore zeolites: SAPO- 
34, SAPO-56, and DNL-6 and a medium pore zeolite ZSM-5 in a 90/10 wt $\%$ GVL/water solvent in order to facilitate simple catalyst recovery and reuse.

\section{Experimental}

\subsection{Catalyst preparation}

\subsubsection{SAPO-34}

SAPO-34 was synthesized employing a procedure reported elsewhere [36]. In a typical synthesis, the $\mathrm{Al}$ source $\left(99.9 \% \mathrm{Al}\left(\mathrm{i}-\mathrm{C}_{3} \mathrm{H}_{7} \mathrm{O}\right)_{3}\right), \mathrm{H}_{3} \mathrm{PO}_{4}$, and deionized water were stirred for $3 \mathrm{~h}$ to form a homogenous solution. Then, Ludox AS-40 colloidal silica ( $40 \mathrm{wt} \%$ suspension in water Sigma-Aldrich) was added and the resulting solution was stirred for $3 \mathrm{~h}$. Tetraethyl ammonium hydroxide (TEAOH, $35 \mathrm{wt} \%$ solution in water Sigma-Aldrich), dipropylamine (99\%, Aldrich), and cyclohexylamine (99\% Sigma-Aldrich) were added and the solution was stirred for 4 days at $60^{\circ} \mathrm{C}$. The solution was then transferred into a stainless steel autoclave and held at $220^{\circ} \mathrm{C}$ for $24 \mathrm{~h}$. Then, the autoclave was cooled down and the solid product was separated by centrifugation and washed three times with deionized water. Finally, SAPO-34 was dried and then calcined at $550^{\circ} \mathrm{C}$ for $5 \mathrm{~h}$. The calcination heating and cooling rates were 1 and $2^{\circ} \mathrm{C} / \mathrm{min}$, respectively.

\subsubsection{SAPO-56}

SAPO-56 was synthesized employing a similar procedure reported elsewhere [37]. A gel composition of: 2.0 TMHD : $0.6 \mathrm{SiO}_{2}: 0.8 \mathrm{Al}_{2} \mathrm{O}_{3}: \mathrm{P}_{2} \mathrm{O}_{5}: 40 \mathrm{H}_{2} \mathrm{O}$ was used (THMD = N,N,N tetra-methyl-hexane-1,6-diamine). In a typical synthesis, alumina was mixed homogeneously with TMHD, orthophosphoric acid, and water. The mixture was vigorously stirred at room temperature for $6 \mathrm{~h}$. After stirring, the resultant gel was transferred into a stainless steel autoclave and held at $200^{\circ} \mathrm{C}$ for $96 \mathrm{~h}$. The SAPO-56 was recovered by centrifugation, dried overnight, and then calcined at $550^{\circ} \mathrm{C}$ for $6 \mathrm{~h}$.

\subsubsection{DNL-6}

DNL-6 was synthesized as reported elsewhere [38]. The synthesis of DNL-6 was as follows: $1.17 \mathrm{~g}$ orthophosphoric acid ( $85 \mathrm{wt} \%)$ and $0.625 \mathrm{~g}$ tetraethyl orthosilicate were mixed with a solution of $3.06 \mathrm{~g}$ aluminium isopropoxide and $13.5 \mathrm{~g}$ deionized water. An aqueous solution of cetyltrimethylammonium bromide (CTAB) was then added, followed by the addition of $1.097 \mathrm{~g}$ of diethylamine (DEA). The solution was stirred during all the above mixing procedures. The specific gel composition for the hydrothermal synthesis was: $1 \mathrm{Al}: 0.8 \mathrm{P}: 0.2 \mathrm{Si}: 1 \mathrm{DEA}: 0.1$ CTAB : $50 \mathrm{H}_{2} \mathrm{O}$. The final gel mixture was transferred into a stainless steel autoclave and held at $200^{\circ} \mathrm{C}$ for $24 \mathrm{~h}$. After $24 \mathrm{~h}$, the autoclave was cooled, and the solid product was collected after centrifugation, washed three times with deionized water, and dried at $110^{\circ} \mathrm{C}$ overnight. Calcination was carried out at $600^{\circ} \mathrm{C}$ for $4 \mathrm{~h}$ to remove organic species using heating and cooling rates of 1 and $2^{\circ} \mathrm{C} / \mathrm{min}$, respectively, to remove organic species. 


\subsubsection{Commercial catalysts}

Amberlyst-70 (A70; DOW Chemical), SAPO-34 (referred to as SAPO-34C to denote commercial; ACSMaterials), and ZSM-5 (Acros Organics) were obtained commercially. The A70 was washed with distilled water until the water had a $\mathrm{pH}$ of 7 and then was crushed (Figure $\mathrm{S} 1 \mathrm{a}$ in the supplemental information). The SAPO-34C and ZSM-5 were used as received.

\subsection{Catalyst characterization}

\subsubsection{Brunauer-Emmett-Teller surface area and porosity}

Materials were characterized by physisorption of $\mathrm{N}_{2}$ at $77 \mathrm{~K}$ (Micromeritics ASAP 2020). Prior to $\mathrm{N}_{2}$ dosing, as-synthesized samples were evacuated at $363 \mathrm{~K}$ and subsequently outgassed under vacuum $(623 \mathrm{~K}, 4 \mathrm{~h})$. To probe changes in surface area porosity that occur during reactions, spent catalysts were also characterized by $\mathrm{N}_{2}$ adsorption. In this case, samples were subjected to a mild outgassing treatment under He flow $(348 \mathrm{~K}, 8 \mathrm{~h})$ followed by evacuation at $323 \mathrm{~K}$ under vacuum $\left(10^{-6}\right.$ Torr) until no further outgassing was observed. This procedure was adopted so as to allow water and other low-vapor pressures species to be evacuated while nonvolatile residues would be largely retained in the catalyst pore structure.

\subsubsection{Acid site determination using temperature-programmed desorption}

Brønsted site densities were determined from molar quantities of ethylene evolved between $570 \mathrm{~K}$ and $870 \mathrm{~K}$ during temperature-programmed desorption (TPD) of ethylamine. Approximately $50 \mathrm{mg}$ of powdered catalyst was loaded into a quartz tube (1/2") on top of a quartz wool plug, and the tube was positioned in a high-temperature furnace (Omega) and connected to a gas flow manifold. Prior to analysis, catalysts were calcined in situ at $673 \mathrm{~K}$ for 4 hours under $50 \mathrm{sccm}$ of air (Airgas, Ultra Zero). Subsequently, the samples were cooled to $423 \mathrm{~K}$ and purged with $100 \mathrm{sccm}$ of He that was dried over molecular sieves. After pretreatment, the samples were held at $423 \mathrm{~K}$ and contacted with ethylamine (99\%, Sigma). Pure ethylamine was introduced into the He stream $(100 \mathrm{sccm})$ through a $50 \mu \mathrm{m}$ capillary tube that served to regulate the ethylamine flow. The cell was then purged with $\mathrm{He}(423 \mathrm{~K}, 100 \mathrm{sccm}, 60 \mathrm{~min})$ and subsequently ramped to $973 \mathrm{~K}(10 \mathrm{~K}$ min-1). During the temperature ramp, the cell effluent was monitored using a mass selective detector (Stanford Instruments RGA 100). Signals corresponding to ethylamine $(\mathrm{m} / \mathrm{z}=30)$ and ethylene $(\mathrm{m} / \mathrm{z}=27)$ were monitored continuously, and Brønsted site densities were calculated from evolved ethylene based on the assumption that one molecule of ethylene forms at one accessible Brønsted site.

Total site densities were determined from molar quantities of ammonia evolved between 423 $\mathrm{K}$ and $1023 \mathrm{~K}$ during TPD of ammonia. After the same pretreatment as described for the Brønsted acid site procedure, the samples were held at $423 \mathrm{~K}$ and contacted with a blend of ammonia (1\% ammonia in He, Airgas) until saturation. The cell was then purged with $\mathrm{He}(423$ $\mathrm{K}, 100 \mathrm{sccm}, 60 \mathrm{~min})$ and subsequently ramped to $1023 \mathrm{~K}\left(10 \mathrm{~K} \mathrm{~min}^{-1}\right)$. During the temperature ramp, the cell effluent was monitored using a mass selective detector (Stanford Instruments RGA 100). The signal corresponding to ammonia $(\mathrm{m} / \mathrm{z}=16)$ was monitored continuously, and acid 
site densities were calculated from evolved ammonia, based on the assumption that one molecule of ammonia desorbs from one accessible acid site.

\subsection{Catalytic reactions}

Experiments were carried out in $10 \mathrm{~mL}$ glass reactors at $463 \mathrm{~K}$ in a heated oil bath with magnetic stirring as previously described by Gurbuz et al. [7]. Dehydration of xylose to furfural was carried out in $4.0 \mathrm{~g}$ of $90 \mathrm{wt} \% \gamma$-valerolactone $(\mathrm{GVL}) / 10 \mathrm{wt} \%$ water solvent with $2 \mathrm{wt} \%$ xylose or switchgrass, which had been previously dried and finely chopped (USDA, Sidney, MT; Figure S1b). Then, catalyst was added in the amount of $0.02 \mathrm{M}$ sulfuric acid or $0.048 \mathrm{~g}$ of solid acid catalyst. The reactors contained triangular stir bars (stirred at $700 \mathrm{rpm}$ ) and were placed in a heated oil bath. The Amberlyst-70 was stored at $378 \mathrm{~K}$ overnight prior to use and all zeolites were stored at $573 \mathrm{~K}$ overnight prior to use. Results were quantified using an HPLC (Agilent 1100; BioRad Aminex HPX-87H column, 0.005 M sulfuric acid mobile phase) with a refractive index detector and a diode array detector. The standard deviation ranged from $1-5 \%$ of the average yield values reported.

\section{Results and discussion}

Of the four small pore zeolites used in this study, three were synthesized: SAPO-34, SAPO-56 and DNL-6, which had XRD patterns consistent with CHA, AFX, and RHO, respectively (Figure S2). The commercially obtained SAPO-34C and ZSM-5 had XRD patterns consistent with CHA and MFI, respectively (Figure S2).

After 0.25 h, ZSM-5, 0.02 M sulfuric acid (SA), and Amberlyst-70 (A70) each resulted in high furfural yields $(70 \%, 63 \%$, and $67 \%$, respectively; Figure 1), which are similar to previously reported results [7]. However, leaching studies (details in supplemental information) were done and furfural yields of $57 \%$ and $52 \%$ were achieved when a solvent previously exposed to A70

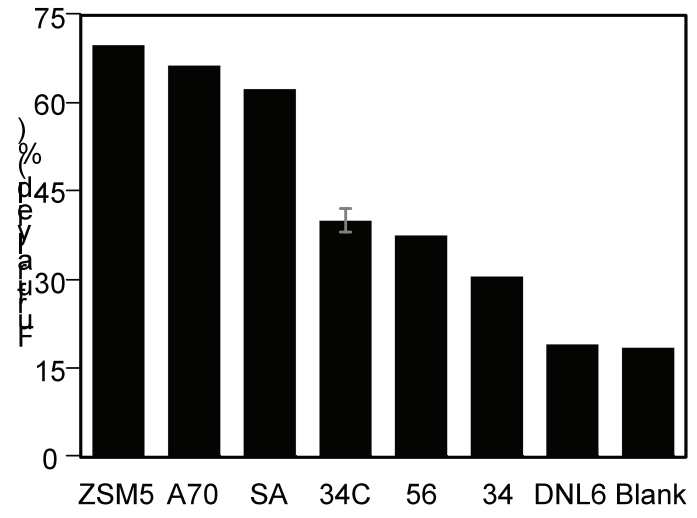

Fig. 1 Furfural yields from $2 \mathrm{wt} \%$ xylose in $90 / 10$ $\mathrm{GVL} /$ water at $463 \mathrm{~K}$. Reaction times of $0.25 \mathrm{~h}$ for ZSM-5, A70 (Amberlyst-70), and 0.02 M sulfuric acid (SA) and $6 \mathrm{~h}$ for all others. Blank = no catalyst; $56,34 \mathrm{C}$, and $34=\mathrm{SAPO}-\mathrm{XX}$.

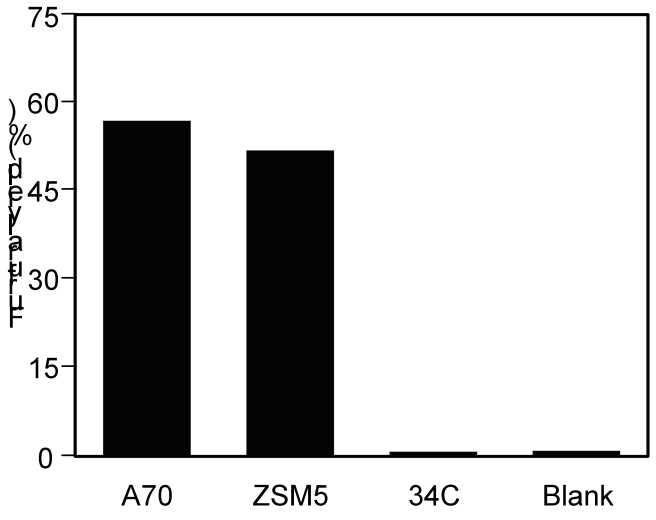

Fig. 2 Furfural yields from leaching reactions with A70, ZSM-5, SAPO-34C, and no catalyst (blank) in 90/10 GVL/H2O at $463 \mathrm{~K}$. 
and ZSM-5, respectively, was used (Figure 2). This indicates that the dehydration reaction was likely catalyzed homogeneously by the acid sites that leached from the A70 and ZSM-5 catalyst.

After $6 \mathrm{~h}$ of reaction time, SAPO-34C, SAPO-56, and SAPO-34 achieved furfural yields of $40 \%, 38 \%$, and $31 \%$, respectively, from xylose (Figure 1). A leaching study using SAPO-34C resulted in low furfural yields that were equivalent to a blank solvent (Figure 2), which confirms that the reaction likely occurred heterogeneously. The furfural yields with the SAPO zeolites are significantly higher than the 19\% yield achieved with DNL-6 and although the 90/10 GVL/water solvent system catalyzed the dehydration reaction without additional catalyst present (blank; $19 \%$ yield), the reaction time required to reach the maximum furfural yields was longer than with catalyst present. With no catalyst, $24 \mathrm{~h}$ was required to reach a maximum furfural yield of $30 \%$, while SAPO-34C, SAPO-56, and SAPO-34 all surpassed 30\% yield within $4 \mathrm{~h}$. Mellmer et al. hypothesized that using GVL as a solvent for xylose dehydration changes the activation energy of the reaction, resulting in increased reaction rates and enhanced product selectivity [39]. Water dissociation to catalyze the xylose dehydration was considered since it becomes increasingly favorable at high temperatures [40,41], but no difference in furfural yield (approximately 30\%) was seen in reactions with no catalyst for $24 \mathrm{~h}$ in pure GVL (contained $0.11 \mathrm{wt} \%$ water as determined by Karl Fischer Titration) and the 90/10 GVL/water as the solvent. This supports the hypothesis that the catalysts, rather than water dissociation, provide the acidity necessary to catalyze xylose dehydration within shorter reaction times, which was also confirmed by Zhang et al. using a $\mathrm{FeCl}_{3} \cdot 6 \mathrm{H}_{2} \mathrm{O}$ catalyst [15].

Although the zeolites contain a significant amount of acid sites (Table 1), in principle, the pore size of the small pore zeolites (3.6-3.8 $\AA$ ) should hinder xylose diffusion because the size of xylose $(6.8 \AA[23,24])$ is significantly larger than the pores. Although there may be surface acid sites contributing to the reaction, the sugar molecules may also be able to access the interior acid sites. Many groups have reported that zeolites have flexible frameworks [44-50], and thus the reaction conditions used may have allowed the SAPO framework to flex, thereby exposing the internal acid sites to xylose. The total acid site concentrations in combination with surface area for the small pore zeolites (Table 1), in general, correlate with furfural yields, indicating that Brønsted acid sites are a critical component for the reaction, which is commonly reported in the

Table 1 Chemical and structural properties of the small pore zeolites, as determined experimentally (acid site and surface area data) and as found in the literature (pore size).

\begin{tabular}{ccccc}
\hline & $\begin{array}{c}\text { Total acid sites } \\
\left(\mu \mathrm{mol} / \mathrm{g}_{\mathrm{cat}}\right)\end{array}$ & $\begin{array}{c}\text { Brønsted acid sites } \\
\left(\mu \mathrm{mol} / \mathrm{g}_{\mathrm{cat}}\right)\end{array}$ & $\begin{array}{c}\text { Surface area } \\
\left(\mathrm{m}^{2} / \mathrm{g}\right)\end{array}$ & $\begin{array}{c}\text { Pore size } \\
(\AA)\end{array}$ \\
\hline SAPO-34C & 980 & 1100 & 510 & $3.8[25]$ \\
SAPO-34 & 370 & 400 & 520 & $3.8[25]$ \\
SAPO-56 & 590 & 240 & 360 & $3.6[43]$ \\
DNL-6 & 270 & 220 & 140 & $3.6[38]$ \\
ZSM-5 & 31 & 31 & 350 & $5.5[44]$ \\
\hline
\end{tabular}


literature [26, 32, 51-53].

Catalyst recyclability experiments, which consisted of the catalysts being acetone washed and heated overnight in between runs (details in supplementary information), showed that SAPO-34C can be recycled and still maintain high catalytic effectiveness with no change to the crystal structure or crystal morphology (Figures S2-S4). The furfural yield only decreased 5\% from the first reaction to the second, and then the yield held constant for the third reaction (Figure 3). The decrease in furfural yield from the first to the second reaction may be related to the surface deposition of carbonaceous species leading to the blockage of some active sites, causing a slight decrease in catalyst activity. Textural properties of fresh and spent samples of ZSM-5, SAPO-34, and SAPO$34 \mathrm{C}$ are presented in the Supporting Information (Figure S5; Table S1). In all cases, SAPO-34 and ZSM-5 exhibit type I isotherms, which are typical of microporous phases. For all samples, there was a considerable decrease in surface area and pore volume after reaction (spent catalysts), which may be associated to the surface deposition of carbonaceous species leading to the pore blockage. Similar conclusions have been previously reported for SAPO-34 by Suprun et. al. [54]. They hypothesized that the relatively high acidity and small pores of SAPO-34 are both factors that lead to accumulation of carbonaceous deposits blocking its surface, which could be potentially avoided with a lower reaction temperature [54]. The furfural yield using recycled A70 initially decreased $7 \%$, but remained constant for the third recycle indicating that although significant leaching occurs, due to the high number of acid sites available, reaction can still take place upon recycle.

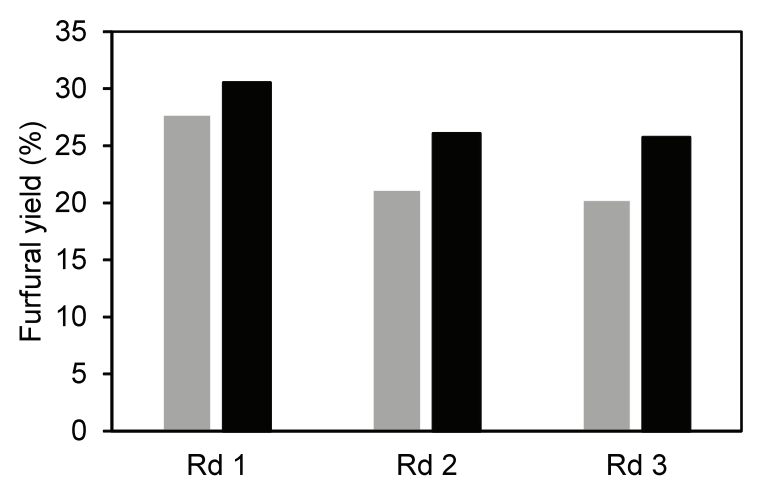

Fig. 3: Recycle reaction results for A70 (gray bars) and SAPO-34C (black bars).

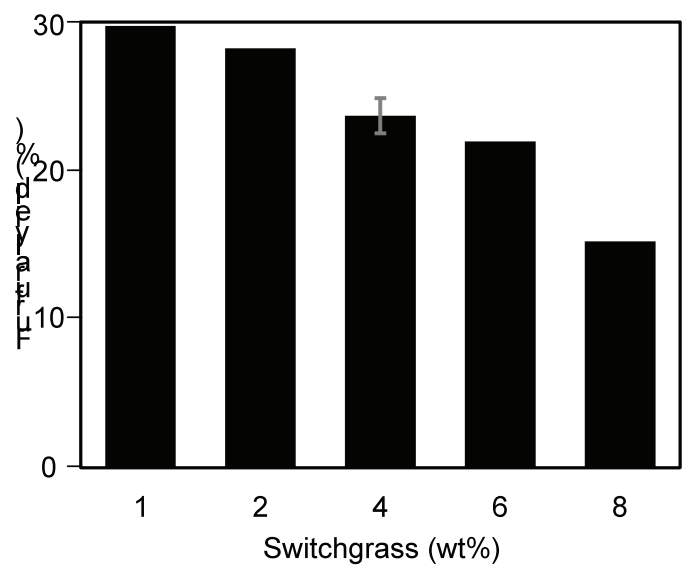

Fig. 4 Furfural yields after $8 \mathrm{~h}$ of reaction with SAPO-34 at $463 \mathrm{~K}$ are compared for various starting amounts of switchgrass in 90/10 $\mathrm{GVL} /$ water.

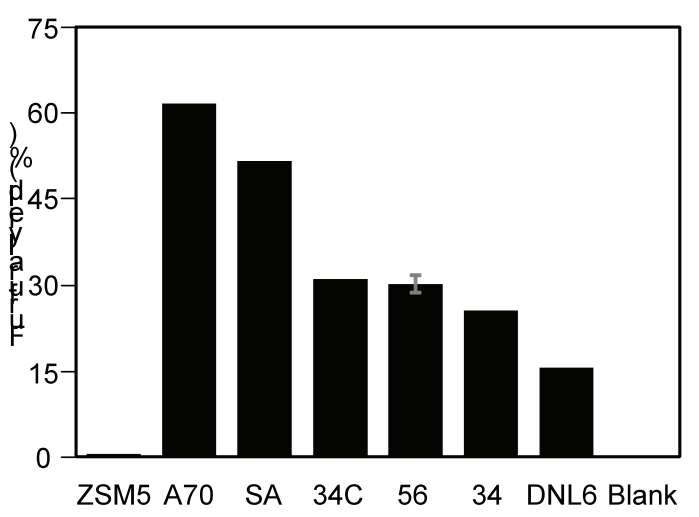

Fig. 5 Furfural yields using $2 \mathrm{wt} \%$ switchgrass in 90/10 GVL/water at $463 \mathrm{~K}$ after $0.5 \mathrm{~h}$ for A70 (Amberlyst-70) \& $0.02 \mathrm{M}$ sulfuric acid (SA) and 24 $\mathrm{h}$ for all others. Blank $=$ no catalyst; 56, 34C, and 34 $=$ SAPO-XX. 
For switchgrass experiments, both the xylose (18 wt $\%)$ and glucose $(31 \mathrm{wt} \%)$ can convert to furfural $[7,15,55,56]$, which was confirmed with glucose experiments that showed formation of furfural and formaldehyde using SA, A70, and SAPO-34C. Therefore, to determine furfural yield, the actual moles of furfural from switchgrass experiments were divided by the initial total moles of xylose and glucose. The 1 and $2 \mathrm{wt} \%$ switchgrass feeds both resulted in virtually complete biomass solubilization and higher furfural yields than with $4 \mathrm{wt} \%$ switchgrass and higher (Figure 4). With switchgrass feeds of 4, 6, and $8 \mathrm{wt} \%$, the solids remaining after reaction were substantial and led to difficult recovery of the catalyst. Therefore, a loading of $2 \mathrm{wt} \%$ switchgrass was chosen for subsequent switchgrass experiments.

Although furfural yields with SAPO catalysts were moderate compared to those with SA and A70 using switchgrass as the feedstock, less than 1\% furfural yield was achieved using no catalyst (blank) or ZSM-5 (Figure 5). This indicates that some type of acid catalyst is required for deconstructing biomass for conversion to furfural and that the low concentration of Bronsted acid sites on ZSM-5 (Table 1) may be deactivated by monovalent cations (e.g., $\mathrm{Na}^{+}$) present upon biomass deconstruction.

\section{Conclusions}

In conclusion, moderate furfural yields were achieved from both xylose and switchgrass with small pore zeolites SAPO-34 and SAPO-56 in 90/10 GVL/water, which to the authors' best knowledge is the first time zeolites and in particular, small pore zeolites, have been used to convert switchgrass thermochemically. The small pore zeolites produced higher furfural yields than reactions with no catalyst in all cases at a given time and, although higher furfural yields were achieved with SA and A70, the results of the leaching experiments indicated significant acid site leaching and homogeneous catalysis with A70 and ZSM-5, while SAPO-34C showed insignificant leaching and likely, heterogeneous catalysis. The zeolites were easy to separate and reuse following a reaction and SAPO-34C catalyst was recycled multiple times with only a slight drop in furfural yield. The overall furfural yields achieved from xylose with the SAPO zeolites were less than with other zeolites, such as mordenite, but these small pore zeolites may be rationally designed to increase the yield from biomass reactions.

\section{Acknowledgements}

Wettstein acknowledges the Vice President of Research at Montana State University for the research funds in order to complete this research and thanks Rich Noble for his valuable discussion. The authors thank Brett Allen from the USDA at Sydney, MT for providing the switchgrass used in this study. Carreon thanks the Coors Foundation for financial support.

\section{References}

[1] R. Sahu, P.L. Dhepe, Chemsuschem 5 (2012) 751-761.

[2] L.T. Fan, M.M. Gharpuray, Y.H. Lee, Cellulose Hydrolysis, Springer-Verlag, Berling, Germany, 1987.

[3] P. Gallezot, Chem. Soc. Rev. 41 (2012) 1538-1558. 
[4] P. McKendry, Bioresour. Technol. 83 (2002) 37-46.

[5] K.A. Seck, E.S. Olson, (2013).

[6] J.P. Lange, E. van der Heide, J. van Buijtenen, R. Price, Chemsuschem 5 (2012) 150-166.

[7] E.I. Gurbuz, J.M.R. Gallo, D.M. Alonso, S.G. Wettstein, W.Y. Lim, J.A. Dumesic, Angew. Chem., Int. Ed. 52 (2013) 1270-1274.

[8] Y. Lu, N.S. Mosier, Biotechnol. Prog. 23 (2007) 116-123.

[9] H. Danner, R. Braun, Chem. Soc. Rev. 28 (1999) 395-405.

[10] J.R. Jensen, J.E. Morinelly, K.R. Gossen, M.J. Brodeur-Campbell, D.R. Shonnard, Bioresour. Technol. 101 (2010) 2317-2325.

[11] C.E. Wyman, B.E. Dale, R.T. Elander, M. Holtzapple, M.R. Ladisch, Y.Y. Lee, Bioresour. Technol. 96 (2005) $2026-2032$.

[12] J. Geboers, S. Van de Vyver, K. Carpentier, P. Jacobs, B. Sels, Chem. Comm. 47 (2011) 5590-5592.

[13] P. Maki-Arvela, T. Salmi, B. Holmbom, S. Willfor, D.Y. Murzin, Chem. Rev. 111 (2011) 5638-5666.

[14] S.G. Wettstein, D.M. Alonso, Y.X. Chong, J.A. Dumesic, Energ Environ Sci 5 (2012) 8199-8203.

[15] L. Zhang, H. Yu, P. Wang, Y. Li, Bioresour. Technol. 151 (2014) 355-360.

[16] D. Yamaguchi, M. Kitano, S. Suganuma, K. Nakajima, H. Kato, M. Hara, J. Phys. Chem. C 113 (2009) 3181-3188.

[17] D.-m. Lai, L. Deng, Q.-x. Guo, Y. Fu, Energ Environ Sci 4 (2011) 3552-3557.

[18] S. Van de Vyver, L. Peng, J. Geboers, H. Schepers, F. de Clippel, C.J. Gommes, B. Goderis, P.A. Jacobs, B.F. Sels, Green Chem. 12 (2010) 1560-1563.

[19] X. Shi, Y. Wu, H. Yi, G. Rui, P. Li, M. Yang, G. Wang, Energies (2011).

[20] Z.K. Xie, Z.C. Liu, Y.D. Wang, Q.H. Yang, L.Y. Xu, W.P. Ding, Int. J. Mol. Sci. 11 (2010) 2152-2187.

[21] D.M. Alonso, J.M.R. Gallo, M.A. Mellmer, S.G. Wettstein, J.A. Dumesic, Catal Sci Technol 3 (2013) 927931.

[22] P.D. Carà, M. Pagliaro, A. Elmekawy, D.R. Brown, P. Verschuren, N.R. Shiju, G. Rothenberg, Catal Sci Technol 3 (2013) 2057-2061.

[23] M.M. Antunes, S. Lima, A. Fernandes, M. Pillinger, M.F. Ribeiro, A.A. Valente, Appl Catal a-Gen 417 (2012) 243-252.

[24] E. Sjoman, M. Manttari, M. Nystrom, H. Koivikko, H. Heikkila, J. of Mem. Sci. 292 (2007) 106-115.

[25] J. Jae, G.A. Tompsett, A.J. Foster, K.D. Hammond, S.M. Auerbach, R.F. Lobo, G.W. Huber, J. Catal. 279 (2011) 257-268.

[26] S.G. Wettstein, D.M. Alonso, E.I. Gürbüz, J.A. Dumesic, Curr. Opin. Chem. Eng. 1 (2012) 218-224.

[27] E. Nikolla, Y. Roman-Leshkov, M. Moliner, M.E. Davis, Acs Catal 1 (2011) 408-410.

[28] D.W. Fickel, E. D'Addio, J.A. Lauterbach, R.F. Lobo, App. Catal. B: Environ. 102 (2011) 441-448.

[29] S. Wilson, P. Barger, Micropor Mesopor Mat 29 (1999) 117-126.

[30] C. Moreau, R. Durand, D. Peyron, J. Duhamet, P. Rivalier, Ind. Crops Prod. 7 (1998) 95-99.

[31] S. Lima, M.M. Antunes, A. Fernandes, M. Pillinger, M.F. Ribeiro, A.A. Valente, Appl Catal a-Gen 388 (2010) 141-148.

[32] R. O'Neill, M.N. Ahmad, L. Vanoye, F. Aiouache, Ind Eng Chem Res 48 (2009) 4300-4306.

[33] S.B. Kim, S.J. You, Y.T. Kim, S. Lee, H. Lee, K. Park, E.D. Park, Korean J. Chem. Eng. 28 (2011) 710716.

[34] S. Lima, A. Fernandes, M. Antunes, M. Pillinger, F. Ribeiro, A. Valente, Catal Lett 135 (2010) 41-47.

[35] M. Moliner, C. Martínez, A. Corma, Chemistry of Materials 26 (2014) 246-258.

[36] M.A. Carreon, S. Li, J.L. Falconer, R.D. Noble, Advanced Materials 20 (2008) 729-732.

[37] S.T. Wilson, R.W. Broach, C.S. Blackwell, C.A. Bateman, N.K. McGuire, R.M. Kirchner, Micropor Mesopor Mat 28 (1999) 125-137.

[38] X. Su, P. Tian, J.Z. Li, Y. Zhang, S.H. Meng, Y.L. He, D. Fan, Z.M. Liu, Micropor Mesopor Mat 144 (2011) 113-119.

[39] M.A. Mellmer, C. Sener, J.M.R. Gallo, J.S. Luterbacher, D.M. Alonso, J.A. Dumesic, Angew. Chem., Int. Ed. 53 (2014) 11872-11875.

[40] N. Akiya, P.E. Savage, Chem. Rev. 102 (2002) 2725-2750.

[41] E. Lam, J.H. Chong, E. Majid, Y. Liu, S. Hrapovic, A.C.W. Leung, J.H.T. Luong, Carbon 50 (2012) 10331043.

[42] X.-g. Lei, S. Jockusch, M. Francesca Ottaviani, N.J. Turro, Photochemical \& Photobiological Sci. 2 (2003) 1095-1100.

[43] Z. Xie, M. Zhu, A. Nambo, J.B. Jasinski, M.A. Carreon, Dalton Trans. 42 (2013) 6732-6735. 
[44] W.C. Conner, R. Vincent, P. Man, J. Fraissard, Catal. Lett. 4 (1990) 75-83.

[45] T. Baimpos, D. Kouzoudis, L. Gora, V. Nikolakis, Chem. Mater. 23 (2011) 1347-1349.

[46] S.G. Sorenson, E.A. Payzant, R.D. Noble, J.L. Falconer, J. Membr. Sci. 357 (2010) 98-104.

[47] M. Yu, S.G. Li, J.L. Falconer, R.D. Noble, Microporous Mesoporous Mater. 110 (2008) 579-582.

[48] K.D. Hammonds, V. Heine, M.T. Dove, J. Phys. Chem. B 102 (1998) 1759-1767.

[49] A. Sartbaeva, S.A. Wells, M.M.J. Treacy, M.F. Thorpe, Nat. Mater. 5 (2006) 962-965.

[50] M.J. Sprague, J. Polym. Sci. Part C: Polym. Lett. 27 (1989) 343-343.

[51] J.M.R. Gallo, D.M. Alonso, M.A. Mellmer, J.H. Yeap, H.C. Wong, J.A. Dumesic, Top Catal 56 (2013) 1775-1781.

[52] V. Choudhary, S.H. Mushrif, C. Ho, A. Anderko, V. Nikolakis, N.S. Marinkovic, A.I. Frenkel, S.I. Sandler, D.G. Vlachos, J. American Chem. Soc. 135 (2013) 3997-4006.

[53] V. Choudhary, S.I. Sandler, D.G. Vlachos, Acs Catal 2 (2012) 2022-2028.

[54] W. Suprun, M. Lutecki, T. Haber, H. Papp, J. Mol. Catal. A: Chem. 309 (2009) 71-78.

[55] M. Bicker, J. Hirth, H. Vogel, Green Chem. 5 (2003) 280-284.

[56] F. Jin, H. Enomoto, Energ Environ Sci 4 (2011) 382-397. 

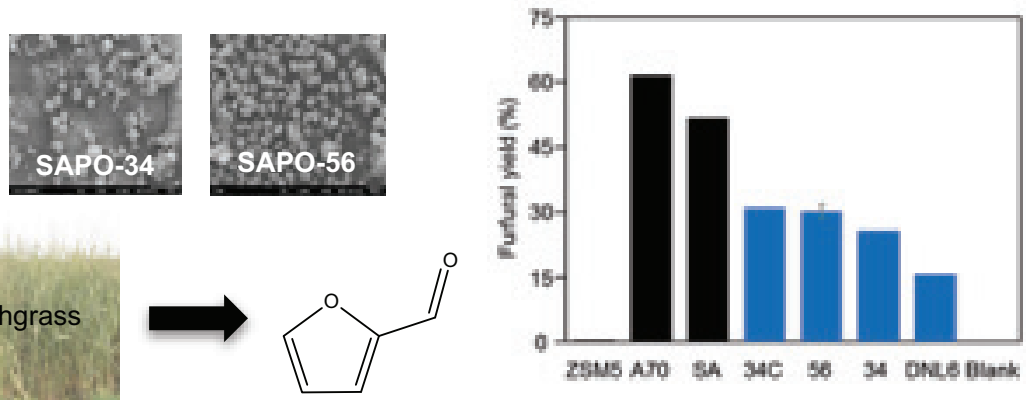

Switchgrass

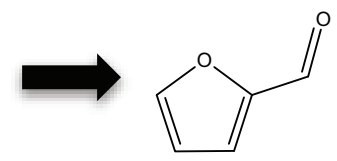

